\title{
PENGHARAPAN DI TENGAH PENGHUKUMAN: SEBUAH TEOLOGI KITAB RATAPAN
}

\author{
Samgar Setia Budhi ${ }^{1}$, Farel Yosua Sualang ${ }^{2}$, Triyono Surahmiyoto ${ }^{3}$ \\ Sekolah Tinggi Teologi Kalimantan ${ }^{1,3}$, Sekolah Tinggi Teologi Injili Indonesia \\ Yogyakarta $^{2}$
}

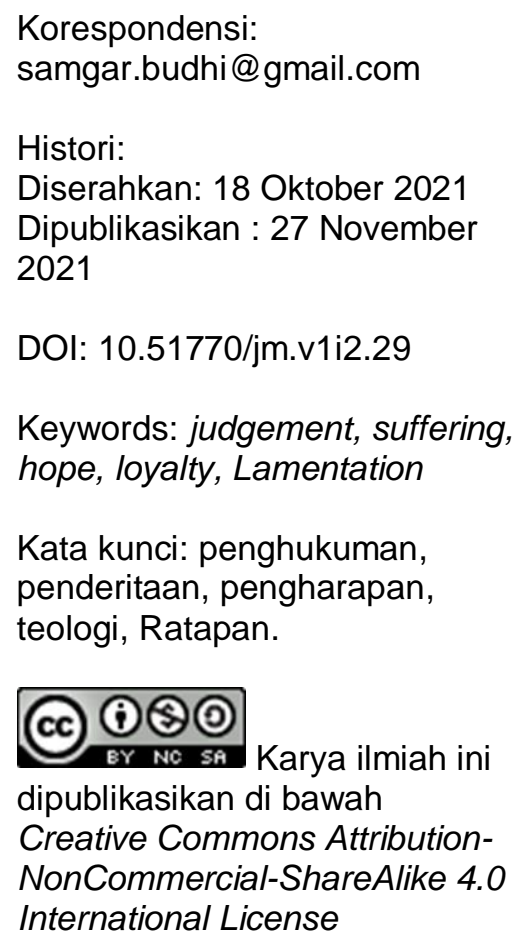

Abstract. The Book of Lamentations is a book rich in theological reflections on condemnation and hope. The reflection is enriched by the type of literature used, poetry with the lamentation subgenre, and with an acrostic and stratified text structure. The richness and depth of his theological contemplation encourage the research of this book in biblical theology. The purpose of this study is to find biblical theology of punishment and hope according to the Book of Lamentations. The method used in this study is a synthesis method by finding literary forms, book structures, major themes, and developing these themes by investigating the text based on the structure of the book, as well as investigating various supporting literature. Through this research, it was found that the sins of the people can lead to God's judgment and that punishment causes painful suffering. The right response is to recognize sin and repent and hope in God. God's faithful love and mercy are a strong foundation of hope for believers.

Abstrak. Kitab Ratapan adalah kitab yang kaya dengan perenungan teologis tentang penghukuman dan pengharapan. Perenungan itu diperkaya dengan jenis sastra yang digunakan, puisi dengan subgenre ratapan, dan dengan struktur teks yang akrostik dan bertingkat. Kekayaan dan kedalaman perenungan teologinya mendorong dilakukannya penelitian terhadap kitab ini secara teologi biblika. Tujuan penelitian ini adalah untuk menemukan teologi biblika tentang penghukuman dan pengharapan menurut Kitab Ratapan. Metode yang digunakan dalam penelitian ini adalah metode sintesis dengan menemukan bentuk sastra, struktur kitab, tema besar, dan mengembangkan tema tersebut dengan menyelidiki teks berdasarkan struktur kitabnya, serta menyelidiki berbagai literatur penunjang. Melalui penelitian ini ditemukan bahwa dosa umat dapat membawa kepada penghukuman Allah dan penghukuman itu mengakibatkan penderitaan yang menyakitkan. Respon yang tepat adalah menyadari dosa dan bertobat serta berharap kepada Allah. Kasih setia dan rahmat Allah adalah dasar pengharapan yang kuat bagi orang percaya. 


\section{PENDAHULUAN}

Kitab Ratapan adalah sebuah karya anonim. Meskipun tradisi Yahudi menghubungkan Ratapan dengan nabi Yeremia, tetapi belakangan ini banyak sarjana yang mengambil posisi netral dengan tidak terlalu memaksakan diri untuk menentukan identitas penulis kitab secara spesifik karena ketidakcukupan bukti-bukti pendukung (Provan 1991; Hillers 1992; Bracke 2000; Garrett and House 2004; Longman III and Dillard 2006).

Kitab Ratapan adalah salah satu kitab dalam Perjanjian Lama yang kaya dengan perenungan teologis seputar penderitaan. Hal ini diakui oleh C. Hassell Bullock yang berpendapat bahwa Kitab Ratapan adalah salah satu risalah teologi yang penting dalam Perjanjian Lama dan memberikan kemewahan serta kepuasan dalam perenungan teologis (Bullock 2002). Kekayaan teologi Kitab Ratapan ini telah mendorong banyak penelitian seputar kitab tersebut. C.W. Miller menelusuri perkembangan penelitian terhadap Kitab Ratapan periode tahun 1990-2002 dan menemukan peningkatan yang signifikan terhadap penelitian Kitab Ratapan melalui disertasi, monograf, dan artikel (Miller 2002). Sebagian besar penelitian yang dilakukan selama periode tersebut menggunakan pendekatan historis-kritis tradisional dan sastra. Fokus penelitiannya berkenaan dengan genre dan pola-pola individual, pola-pola puisi, dan pergeseran pembicara dalam Kitab Ratapan. 
Selanjutnya Heath A. Thomas juga melakukan survei seputar penelitian Kitab Ratapan selama periode 2002-2012 dan menemukan bahwa penelitian historis kritis tradisional masih tetap berlanjut tetapi lebih fokus pada penelitian melalui penyelidikan historiografi yang terjalin dengan teori studi sejarah modern. Selain itu, muncul perkembangan terbaru terhadap penelitian Kitab Ratapan yang berfokus pada 7 pendekatan, yaitu: pendekatan feminis, psikologis, teologis, ekologis, postkolonial, dan resepsi-historis (Thomas 2012).

Penelitian selanjutnya dilakukan oleh Beau Harris dan Carleen Mandolfo yang memfokuskan penelitiannya pada makna dari keheningan Allah dalam Kitab Ratapan. Penelitian ini menemukan bahwa menafsirkan keheningan Allah membutuhkan kesabaran dalam mengevaluasi seluruh bukti, kreativitas dalam mengeksplorasi "ruang negatif" yang ditinggalkan Allah, dan kepekaan serta rasa hormat yang mendalam terhadap suarasuara kesedihan dalam teks dengan tujuan untuk lebih memahami maksud dari diamnya Allah (B. Harris and Mandolfo 2013). Penelitian yang lain dilakukan oleh Robert Williamson Jr. yang berfokus pada trauma dan subyektifitas moral dalam Kitab Ratapan (Williamson Jr. 2015). Adapun penelitian yang dilakukan oleh Indah Sriulina lebih fokus kepada teks Ratapan 3:1-24 sebagai dasar bagi pelayanan pendampingan pastoral korban bencana alam (Sriulina 2016). 
Penelitian ini lebih berfokus kepada penelitian teologi biblika yang menekankan tema penderitaan dan pengharapan dalam Kitab Ratapan. Kekayaan teologi kitab Ratapan tersebut layak untuk terus didalami. Tujuan penelitian ini adalah untuk menemukan teologi biblika tentang penderitaan dan pengharapan menurut Kitab Ratapan dan relevansinya dengan pergumulan umat Allah masa kini. Pemahaman yang benar tentang penderitaan akan menolong umat Allah untuk tetap beriman dan meletakkan pengharapannya kepada Allah yang hidup.

\section{METODE PENELITIAN}

Metode yang digunakan dalam penelitian ini adalah metode sintesis. Metode ini berusaha mendekati sebuah kitab sebagai satu kesatuan dan memahami maknanya sebagai keseluruhan (Subagyo 2004) melalui menemukan tema yang menyatukan perikop-perikop sehingga menghasilkan sebuah teologi biblika Kitab Ratapan (Osborne 2006).

Adapun prosedur yang dilakukan dalam metode ini adalah sebagai berikut: Pertama, mengenali bentuk sastra dan menemukan struktur Kitab Ratapan. Identifikasi bentuk sastra akan menolong dalam menganalisis teks sesuai dengan jenis sastranya. Adapun pemahaman tentang struktur kitab akan membantu dalam menemukan alur dan ide utama kitab. Kedua, menemukan tema besar berdasarkan struktur kitab. Ketiga, mengembangkan tema tersebut dengan menelusuri teks berdasarkan struktur kitabnya. Keempat, menyelidiki berbagai literatur penunjang 
lainnya seperti kamus, ensiklopedi, buku, dan artikel yang berhubungan dengan topik yang diselidiki (Zaluchu 2021).

\section{PEMBAHASAN}

\section{Bentuk Sastra dan Struktur Kitab Ratapan}

Kitab Ratapan adalah kumpulan dari lima puisi, dimana sebagian besar (Rat. 1, 2, dan 4) diawali dengan penggunaan kata seru "Ah" (Ibr. אֵיכָ, 'êk $\underline{k} \hat{a}$ ). Kata ('êk $\underline{k}$ ) adalah sebuah kata pembukaan yang khas dalam nyanyian pemakaman (Holladay 1988). Penggunaan kata tersebut dan kalimat-kalimat pendek yang bernada kesedihan dengan struktur yang sama, menandakan bagian itu adalah ratapan atas tragedi yang dalam.

Ratapan merupakan salah satu subgenre dari puisi yang terdiri dari ratapan individu dan ratapan masyarakat (Klein, Blomberg, and Hubbard Jr. 2016) dan merupakan sebuah doa tentang disorientasi (Longman III 1995). Adapun Kitab Ratapan adalah sebuah puisi yang memiliki jenis sastra ratapan. Kitab ini merupakan kombinasi dari beberapa jenis sastra yang berbeda, yaitu lagu pemakaman (Rat. 1, 2, dan 4), ratapan individu (Rat. 3), dan ratapan komunitas (Rat. 5) (Longman III and Dillard 2006; Longman III 1995). Tetapi studi terbaru cenderung melihat kitab ini secara lebih holistik. Ferris menyimpulkan bahwa Kitab Ratapan harus diklasifikasikan sebagai ratapan komunitas yang serupa dengan yang ditemukan dalam Mazmur (Ferris Jr. 1992). Jadi ketika seseorang mencoba memahami Kitab Ratapan, dia harus melihat penulis kitab 
sebagai pribadi yang bukan saja mewakili dirinya sendiri, melainkan juga mewakili umat secara keseluruhan. Setiap gambaran dan ungkapan yang dinyatakan penulis bukan saja gambaran dan ungkapan yang menyatakan perasaan pribadi, tetapi juga perasaan umat yang diwakilinya.

Adapun struktur Kitab Ratapan terdiri dari struktur akrostik dan bertingkat. Kitab Ratapan terdiri dari lima pasal di mana empat pasal pertama merupakan puisi akrostik dengan variasi gaya. Pasal terakhir tidak berada dalam bentuk akrostik. Meskipun demikian, sesungguhnya pasal tersebut juga dipengaruhi oleh pola puisi akrostik. Kitab Ratapan juga memiliki struktur bertingkat yang puncaknya ada pada pasal 3 . Mengenai hal ini, Tremper Longman III menuliskan bahwa "struktur buku ini adalah materi bertingkat yang kompleks" yang digambarkannya sebagai berikut (Longman III and Dillard 2006):

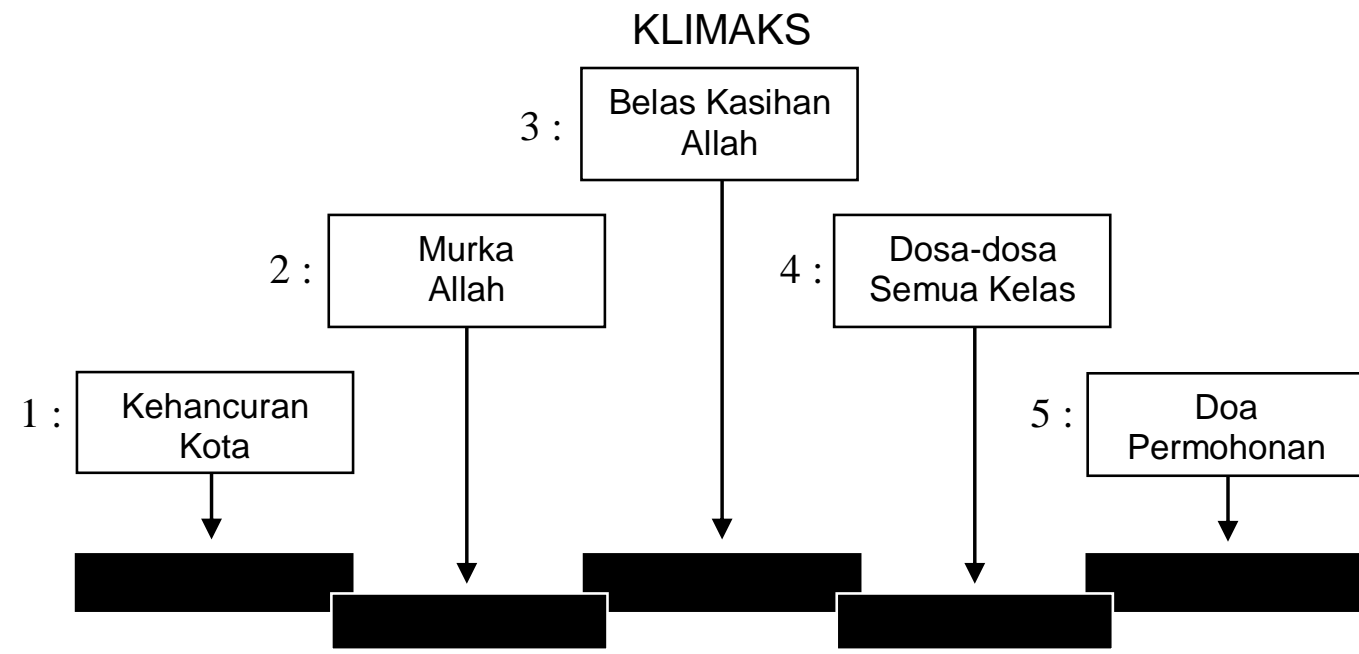

Jadi gambar diatas menunjukkan bahwa fokus Kitab Ratapan terletak pada pasal 3 yang membahas tentang pengharapan akan belas 
kasihan Allah. Adapun pasal 1, 2, 4, dan 5 membahas tentang penderitaan yang dialami umat Allah dan permohonan doa mereka. Dengan mempertimbangkan struktur ini maka bisa dilihat bagaimana isinya menyediakan sesuatu kepada pusat buku secara keseluruhan.

\section{Penghukuman Allah}

Para nabi Perjanjian Lama dipakai Allah bukan untuk membuat ajaran baru maupun mengajarkan Taurat melainkan untuk mengingatkan bangsa Israel agar kembali kepada Dia melalui menaati Taurat (Wood 2005; Green 2005). Oleh sebab itu berita para nabi adalah berita pertobatan, penghukuman, dan pengharapan. Jika umat Allah bertobat, maka mereka akan menerima berkat (Im. 26; UI. 28:1-14). Sebaliknya, jika bangsa itu tidak bertobat, maka mereka akan menerima kutuk (UI. 28:15-68). Demikian juga, meskipun mereka sudah dihukum tetap ada pengharapan akan pemulihan bagi mereka yang kembali kepada Dia.

Nabi Yeremia adalah nabi yang dipakai Allah untuk mengingatkan Kerajaan Selatan akan datangnya penghukuman Allah karena ketidaktaatan mereka (Yer. 1). Pada akhirnya bangsa Israel tetap tegar tengkuk dan menerima penghukuman Allah. Mereka ditaklukkan oleh Babilonia dan secara bertahap penduduknya diangkut ke Babel pada tahun 605, 597 dan 586 sM (Yamauchi 1988).

Kitab Ratapan ditulis sesudah Yerusalem dihancurkan oleh bangsa Babel pada tahun $\pm 587 / 586$ SM. Penulis kitab menjadi saksi mata 
peristiwa penyerbuan dan penghancuran Yerusalem serta penawanan mereka ke Babel. Penulis meratapi kehancuran bangsa Yehuda sambil mengakui dosa-dosa bangsanya dan memohon belas kasihan serta pemulihan yang dari TUHAN. Penulis melalui setiap ungkapan dan gambaran yang dinyatakannya ingin menunjukkan siapa sesungguhnya Allah yang telah menghukum umat-Nya, mengapa Dia menghukum, dan apa akibat dari penghukuman-Nya.

\section{Allah adalah Hakim}

Berbagai pernyataan, ungkapan, dan gambaran yang dinyatakan penulis kitab menunjukkan tindakan Allah sebagai Hakim yang mengadili, menetapkan dan menimpakan bencana atas umat-Nya. Penulis kitab dalam ratapannya atas kehancuran Yerusalem menegaskan bahwa Allah menetapkan tetangga-tetangga Yehuda sebagai musuhnya (Rat. 1:17).

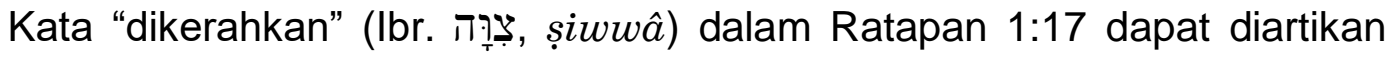
"mengirimkan" (Koehler and Baumgartner 2000). Jadi kata itu menunjukkan bahwa Allah yang menetapkan malapetaka itu atas Yerusalem. Penggalan dari Ratapan 1:5 yang berbunyi "Sungguh, TUHAN membuatnya merana" menegaskan bahwa Allah yang menyebabkan

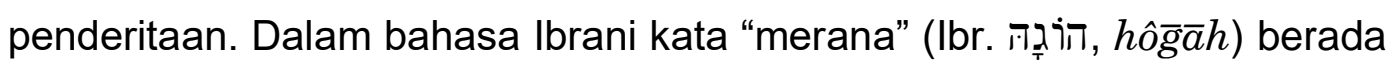
dalam bentuk hiphil yang menyatakan kausatif atau menyebabkan sesuatu terjadi (Waltke and O'Connor 1990; Arnold and Choi 2018) dan bisa diterjemahkan "berdukacita, tersiksa" (Holladay 1988). Kata ini muncul 
kembali dalam Ratapan 1:12 dan 3:32. Hal ini menegaskan bahwa Allah yang menyebabkan atau membuat umat-Nya menderita atau tersiksa. Selain itu, berbagai ungkapan dan gambaran luar biasa yang dituliskan oleh penulis kitab dalam ayat 13-16 juga menunjukkan bahwa Allah yang menimpakan hukuman yang mengakibatkan penderitaan luar biasa.

Dalam puisi kedua (Rat. 2), penulis kitab Ratapan juga mengungkapkan bagaimana Allah menetapkan dan menimpakan bencana atas umat-Nya. Yeremia 2:17 mengatakan "TUHAN telah menjalankan yang dirancangkan-Nya, la melaksanakan yang difirmankan-Nya, yang diperintahkan-Nya dahulu kala...." Bahkan jauh sebelumnya nabi Yesaya juga pernah mengingatkan akan datangnya bencana atas umatnya (2 Raj. 20:17). Pernyataan ini secara tegas menunjukkan bahwa Allah yang menetapkan bencana atas umat-Nya. Ungkapan-ungkapan dalam ayat 18 seperti "Tuhan menyelubungi," "Keagungan Israel dilemparkan-Nya," "Tuhan memusnahkan," "la menghancurkan," "la mencampakkan," "la mematahkan," "menarik kembali tangan kanan-Nya," "membakar Yakub," "la membidikkan panah-Nya," "membunuh segala yang menyenangkan mata," "memuntahkan geram-Nya," "la menghancurkan Israel," "meremukkan segala purinya," "mempuingkan benteng-bentengnya," "memperbanyak susah dan kesah," "la melanda kemah-Nya," "menghancurkan tempat pertemuan-Nya," TUHAN membuang mezbahNya," "meninggalkan tempat kudus-Nya," "menyerahkan kepada tangan 
seteru," "TUHAN telah memutuskan untuk mempuingkan," "la mengukur semuanya," "la tak menahan tangan-Nya," dan "la menjadikan berkabung" menunjukkan bagaimana Allah murka dan menimpakan hukuman atas Yehuda. Bahkan beberapa diantara kata kerja tersebut menggunakan bentuk Hiphil (Rat. 2:1, 2, 3, 5, 7, 8) yang menyatakan causative active, artinya Allah penyebab dari penderitaan umat (Arnold and Choi 2018).

Puisi ketiga (Rat. 3) juga memberikan petunjuk bahwa Allah menetapkan dan menimpakan bencana atas umat-Nya. Jawaban dari pertanyaan retoris dalam Ratapan 3:37-38 menegaskan bahwa Allah yang memerintahkan apa yang terjadi pada umat-Nya. Kemudian Ratapan 3:1, 43-45 menunjukkan bahwa Allah yang menyebabkan kesengsaraan itu.

Dalam puisi keempat (Rat. 4), khususnya dalam Ratapan 4:11, penulis menggunakan kata-kata Ibrani yang memiliki makna intensif secara paralel untuk menunjukkan tindakan Allah yang kuat untuk

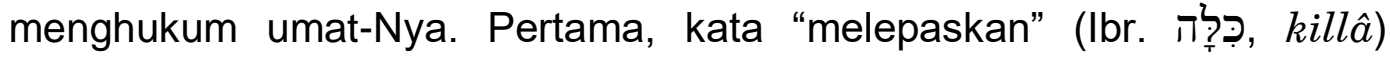
berada dalam bentuk Piel yang memiliki fungsi intensif dan bisa diartikan "memenuhkan." Allah bukan sekedar melepaskan amarah, tetapi memenuhkan amarah-Nya atas Sion (Koehler and Baumgartner 2000). Kata ini ingin menegaskan bahwa Allah melepaskan amarah-Nya yang penuh sehingga keadilan ilahi dipuaskan. Kedua, kata "mencurahkan" (Ibr. 幽, $\breve{s} \bar{a} \bar{p} a \underline{k}$ ) bisa diartikan "menuangkan" yang meskipun dalam bentuk Qal tetapi harus dipahami sejajar dengan kata "memenuhkan." Ketiga, 
"menyalakan" berada dalam bentuk Hiphil yang memiliki fungsi causative active yang artinya "menyebabkan berkobar atau mengobarkan" (Arnold and Choi 2018).Keempat, kata "memakan" berada dalam bentuk Qal dan paralel dengan kata "mengobarkan" sehingga kata itu bisa diartikan "melahap." Keempat kata kerja ini secara paralel menggambarkan suatu keadaan yang sangat menyakitkan tentang Sion dimana tempat itu telah hancur oleh api (Gilchrist 1980).

Jika mencermati Ratapan 2:17, umat Allah seharusnya tidak terkejut dengan hukuman ilahi ini, karena jauh sebelumnya Dia telah menetapkan itu. Ayat ini menyebutkan bahwa peringatan Allah telah disampaikan melalui para nabi-Nya sepanjang sejarah Israel, sejak Musa (Im. 26; Ul. 28) sampai puncaknya dengan Yeremia dan nabi-nabi lain terkemudian sesudah pembuangan. Pesan pokok para nabi itu tetap sama sejak jaman Musa: ketaatan akan mendatangkan berkat Allah; sedangkan ketidaktaatan akan mendatangkan kutuk.

Penulis kitab ratapan dalam melukiskan Allah sebagai hakim, menekankan murka TUHAN $(1: 12 ; 2: 6)$ dan akibatnya yang membawa kehancuran. Kata bahasa Ibrani yang diterjemahkan dengan "murka" muncul di \pm 10 tempat dalam Kitab Ratapan. Ada tiga kata bahasa Ibrani dalam kitab ini yang diterjemahkan dengan murka atau marah, yaitu:

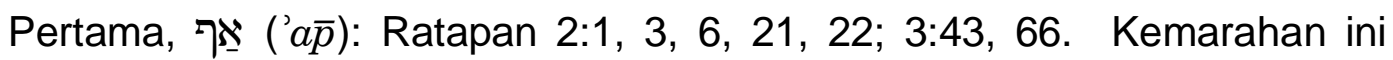
diekspresikan dalam penampilan lubang hidung yang memberikan 
penekanan khusus pada aspek emosional kemarahan dan kemurkaan (Van Groningen 1980a). Kata ini Kedua, הָרוֹן (hārôn): Ratapan 1:12; 4:11. Kata ini hanya digunakan untuk merujuk kepada Allah dan menunjukkan keganasan dari kemarahan TUHAN (Wood 1980). Ketiga, קצבְך (q $(q \bar{a} s \underline{p})$ : Ratapan 5:22. Kata ini menyatakan kemarahan yang muncul dari hubungan yang tidak baik antara dua orang atau lebih (Van Groningen 1980b). Ketika penulis kitab meratapi kehancuran Yerusalem (Rat. 1), dia menghubungkannya dengan murka Allah yang dijelaskan dalam pasal 2.

Kitab Ratapan juga menjelaskan tentang murka Allah dengan menggunakan berbagai metafora. Penulis melukiskan hukuman TUHAN dengan api yang menyala-nyala $(1: 13 ; 2: 3)$, jerat dari jaring pemburu (1:13), injakan pemeras anggur (1:15), bidikan anak panah (2:4; 3:12-13), serangan penyakit (3:4), penawanan di tempat yang gelap (3:2, 6-8), serangan binatang buas (3:10-11), dan tekanan ke dalam debu (3:16). Meskipun metafora tentang murka Allah digambarkan begitu luar biasa, tetapi murka-Nya berbeda dengan manusia karena murka Allah adalah murka yang terkendali dan mempunyai dasar yang sangat kuat yaitu dosa umat-Nya (Ryken, Wilhoit, and Longman III 2011a).

\section{Akibat dari Hukuman Allah: Keterpurukan}

Akibat dari hukuman Allah digambarkan secara jelas dan terinci oleh penulis kitab untuk mendorong tanggapan ilahi yang positif atas 
permohonannya untuk dikasihani. Pertama, Yerusalem mengalami perubahan dari yang tadinya terhormat menjadi hina. John F. Walvoord dan Roy B. Zuck mendaftarkan tiga perubahan kota Yerusalem dari Ratapan 1:1, yaitu: satu, populasi penduduknya berkurang. Kota yang dahulu ramai, sekarang menjadi terpencil. Dua, posisi ekonominya berubah. Kota yang dahulu agung, sekarang menjadi seperti seorang janda. Tiga, posisi sosialnya berubah. Kota yang dahulu bagaikan ratu, sekarang menjadi jajahan (Walvoord and Zuck 1985). Selain itu, pujipujian tentang Sion yang menggambarkan kota itu sebagai "kota yang paling indah" dan "kesukaan dunia semesta" (Rat. 2:15; bdg. Mzm. 50:2 dan 48:3), berubah menjadi cercaan oleh musuh-musuhnya dan mereka girang melihat kekalahannya (Rat. 1:7; 2:15-16). Hal itu menimbulkan duka yang mendalam dan tidak seorang pun menghiburnya (Rat. 1:2).

Kedua, penduduk Yehuda diangkut ke Babel sebagai budak (Rat. 1:3-6) tanpa seorang pun yang menghiburnya $(1: 16-17,21)$. Anakanaknya, yang dulu dianggap seperti emas berharga, kini diperlakukan seperti belanga biasa dari tanah (4:1-2). Ketiga, banyak terjadi kekejaman seperti pembunuhan $(2: 21 ; 4: 9)$, penawanan di pengasingan $(1: 3,5,18)$, pemerkosaan (5:11), penghinaan terhadap para pemimpin (5:12), dan kerja paksa bagi para pemuda (5:13). Keempat, ada kelaparan yang mengerikan. Kelaparan terjadi dimana-mana yang membawa kepada 
kematian $(1: 11,19 ; 2: 11-12,19,40 ; 4: 9-10 ; 5: 9)$ sehingga ada yang nekat memakan anak mereka sendiri (Chisholm Jr. 2005).

Kelima, Allah berdiam diri karena kenajisan mereka (3:44-45). Dalam beberapa hal, dosa mereka dianggap lebih buruk daripada dosa Sodom (4:6). Keenam, norma agama dan kemasyarakatan hancur berantakan. Berbagai perayaan agama di Yehuda telah berhenti (1:4; 2:6), Bait Suci dinajiskan $(1: 10 ; 2: 7)$ dan para imam dan nabi dibunuh (2:20). Tidak ada lagi penyataan ilahi melalui para nabi (2:9) karena masyarakat lebih mempercayai pesan-pesan para nabi palsu (2:14). Ketujuh, para pemimpin tidak dihargai. Para pemimpin masyarakat dihina (4:7-8; 5:12) dan ditawan ke pengasingan (2:9). (Chisholm Jr. 2005).

\section{Dasar Penghukuman Allah: Dosa Umat-Nya}

Penulis Kitab Ratapan secara pribadi maupun mewakili umat mengakui segala pelanggaran yang telah dibuat oleh bangsanya. Penulis tidak berusaha membenarkan bangsanya, tetapi juga tidak menuduh Allah berlaku yang tidak adil. Sebaliknya, dia mengakui bahwa bangsanya pantas menerima hukuman karena dosa-dosa mereka.

Ada beberapa hal yang disebutkan penulis kitab tentang dosa-dosa

umat Allah. Pertama, Penduduk Yerusalem banyak melakukan pelanggaran kepada Allah (Rat. 1:5, 22) dan dikatakan sebagai najis (Rat.

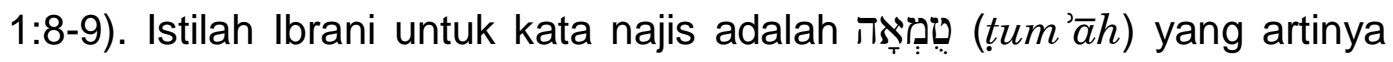
keadaan ketidakbersihan ritual atau seremonial (Koehler and Baumgartner 
2000). Istilah ini mengacu pada keadaan kenajisan ritual dan secara khusus untuk kenajisan seksual (Bil. 5:19), massa yang kotor (Yeh 24:11; 2 Taw 29: 16), kenajisan ritual (Im 16:16, 19; Yeh 22:15; 24:13; 36:25, 29; 39:24; Zak 13:2), kenajisan saat menstruasi (Im 15: 25, 26, 30; 18:19; Yeh 36:17), dan daging yang tercemar (Hak 13:7, 14) (bdg. King and Stager 2010). Ryken menambahkan bahwa keadaan najis juga bisa dikenakan pada dosa dan kefasikan, orang dari bangsa lain, dan setan atau roh jahat (Ryken, Wilhoit, and Longman III 2011b). Jadi kata tersebut menegaskan ketidakbersihan umat karena pelanggaran terhadap ketetapan Allah.

Kedua, memberontak terhadap Allah. Tiga kali dosa bangsa itu dikatakan sebagai "pemberontakan" (Ibr. מָרזה, mārâ) terhadap TUHAN (Rat. 1:18, 20; 3:42). Ratapan 1:18 menyebutkan bahwa pemberontakan itu dilakukan terhadap mulut (Ibr. הִִ̣, peh) yang merupakan metonimi dari perkataan atau firman Allah. Jadi, mereka telah melawan perintah Allah. Meskipun demikian, umat tidak boleh mengeluh atas hukuman Allah (Rat. 3:39) karena TUHAN adalah benar (Rat. 1:18) dan adil (Rat. 3:34-36). Hal ini menegaskan bahwa Allah berhak untuk menghakimi mereka.

Ketiga, ketidakadilan ditengah masyarakat (Rat. 3:34-36). Para nabi dan para imam telah berbuat kejam (Rat. $4: 13$ ) dan tidak menyatakan kebenaran melainkan menyesatkan bangsa itu (Rat. 2:14). Pesan para nabi palsu ialah ajaran tentang keyakinan bahwa Yerusalem tidak mungkin dibinasakan karena itu adalah tempat kediaman Allah sendiri 
(bdg. 4:12). Para nabi palsu telah menyelewengkan cita-cita ideal teologis yang dinyatakan dalam puji-pujian Sion (bdg. Mzm. 46, 48, 76). Mereka mengubah cita-cita itu menjadi janji tanpa syarat dan mengabaikan prasyarat moral-etis untuk merealisasikannya. Kejatuhan Yerusalem pada tahun 586 SM membukakan keyakinan palsu mereka dan menegaskan satu kebenaran teologis, yaitu: umat yang berdosa dan memberontak tidak layak menuntut perlindungan-Nya (Chisholm Jr. 2005).

Keempat, kecenderungan untuk bersandar pada bangsa-bangsa lain (Rat. 4:17). Yeremia 37:3-5 mencatat bagaimana Raja Zedekia mendua hati dengan meminta pertolongan TUHAN tetapi disisi lain menantikan pertolongan Mesir untuk membebaskan Kerajaan Yehuda dari Kasdim. Jelas bahwa TUHAN tidak menghendaki demikian sehingga Dia mengutus Yeremia untuk mengingatkan Raja Zedekia akan kembalinya Kasdim (Yer. 37:6-10). Peringatan TUHAN terbukti dengan kembalinya Raja Nebukadnezar untuk meruntuhkan Yehuda dan mengejar Raja Zedekia serta mengeksekusinya (Yer. 52:4-11; bdg. Rat. 4:19-20). Penulis Kitab Ratapan mengakui kesalahan bangsanya dengan mengatakan sia-sia mengharapkan pertolongan dari bangsa lain (Rat. $4: 17)$.

\section{Pengharapan Di Tengah Penderitaan}

Struktur Kitab Ratapan yang bertingkat dengan klimaksnya pada pasal 3 menunjukkan bahwa Ratapan 3 merupakan puncak dari 
perenungan dan ratapan penulis kitab terhadap penderitaan bangsanya. Setelah meratapi kehancuran kota Yerusalem (Rat. 1), penulis mengakui segala pelanggaran yang telah dilakukan umat sehingga Allah murka terhadap mereka. Penjelasan dan gambaran tentang murka Allah atas umat-Nya diuraikan secara panjang lebar dalam Ratapan 2. Meskipun hukuman Allah mengerikan dan keadaan kota serta bangsanya sangat menyedihkan, tetapi harapan untuk masa depan tetap ada. Tanggapan yang tepat terhadap hukuman Allah ialah pertobatan sejati dan doa yang tulus memohon agar kemurahan-Nya dipulihkan. Jadi Ratapan 3 sesungguhnya adalah respon penulis kitab terhadap penderitaan yang dialami dirinya bersama dengan bangsanya. Respon itu berlanjut sampai kepada pasal terakhir kitab. Bagaimana respon penulis kitab Ratapan terhadap murka Allah yang membuat bangsanya menderita?

\section{Memahami Hakikat Penderitaan}

Pasal 3 diawali dengan pernyataan yang tegas tentang pengalaman penulis kitab sebagai saksi mata dari penderitaan bangsa Yehuda oleh karena murka Allahnya. Ratapan 1:1 menyebutkan "Akulah orang yang melihat sengsara disebabkan cambuk murka-Nya." Dia adalah saksi mata langsung dari penderitaan Yehuda karena dosa-dosa mereka yang membawa kepada penghukuman Allah.

Selanjutnya dalam ayat 2-17 penulis kitab mengungkapkan pengalamannya sebagai saksi mata itu. Dia menyadari dan merasakan 
bersama-sama dengan bangsanya bahwa murka Allah itu sungguh menyakitkan. Ayat-ayat itu memberikan ringkasan tentang campur tangan Allah dan beratnya kesusahan yang dialami penulis dan bangsanya. Penderitaan itu digambarkan secara dramatis sebagai berikut: hidup penuh dengan kegelapan dan hukuman Allah (Rat. 3:2-3), kesehatannya terganggu dan hidup penuh kepedihan (Rat. 3:4-6), tidak ada jalan keluar dan didiamkan Allah (Rat. 3:7-9), menjadi target serangan (Rat. 3:10-13), bahan ejekan dan penuh dengan kepahitan (Rat. 3:14-17). Itu semua terjadi karena umat memberontah terhadap firman Allah (Rat. 1:18) sehingga membuat Allah murka dan menghukum mereka. Mereka telah berbuat dosa secara luar biasa dan layak untuk dimurkai Allah.

Penderitaan yang begitu berat itu digambarkan oleh penulis kitab

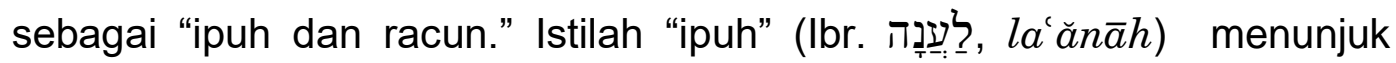
kepada tanaman herbal yang rasanya pahit. Istilah ini selalu digunakan secara metafora untuk menunjukkan kepahitan (Koehler and Baumgartner 2000). Adapun istilah "racun" (Ibr. ראש, $r \bar{o} \breve{s})$ adalah sebuah tanaman beracun yang tidak spesifik di Babilonia (White 1980). Kemunculan 2 kata benda itu secara bersama-sama menegaskan gambaran dari penderitaan yang sangat berat bagaikan racun yang sangat pahit. Begitu beratnya penderitaan itu sampai membuat dia menyangka tidak ada lagi kemasyurannya dan harapannya kepada Allah (Rat. 3:18). Meskipun demikian, dia tetap berusaha untuk memohon kepada Allah agar 
mengingat dia dalam penderitaannya itu (Rat. 3:19). Setiap kali penulis kitab mengingat penderitaannya, semakin merasa tertekan jiwanya (Rat. 3:20). Tetapi dibalik semua ungkapan dan gambaran yang diberikan, pengakuan ini merupakan pernyataan kesadarannya akan penderitaan dan membawa penulis untuk berharap kepada Allah.

\section{Memahami Hakikat Rahmat dan Kasih Setia Allah}

Respon kedua yang dinyatakan penulis kitab adalah keyakinannya kepada Allah. Keberadaan bangsa itu sesungguhnya merupakan pertanda positif. Allah sebenarnya dapat membinasakan sama sekali bangsanya, tetapi sebaliknya Dia melindungi beberapa orang melewati hari-hari penghukuman. Penulis kitab memahami ini sebagai pernyataan kasih setia, rahmat dan kesetiaan Allah (3:22-23 Dia mengambil keputusan untuk memperhatikan karakter Allah dan berdasarkan keyakinan akan karakter Allah itu, dia belajar untuk tetap berharap akan pemulihan yang dari Dia. Kata "rahmat" berasal dari kata Ibrani רִחמִִים (rahămîm) yang mempunyai arti belas kasihan atau kasih sayang Allah yang berakar pada cinta dan kasih karunia-Nya yang cuma-cuma (Coppes 1980). Hal ini merupakan tanggapan penuh perasaan Allah terhadap kebutuhan umat-Nya (Chisholm Jr. 2005). Sedangkan kata "kasih setia"

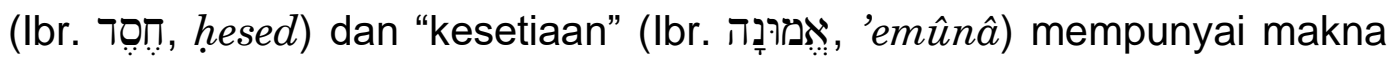
yang sangat berkaitan. Dua kata itu menerangkan kesetiaan Allah kepada umat perjanjian-Nya dan pada janji-janji yang diucapkan bagi mereka (R. 
L. Harris 1980). Allah melalui perjanjian-Nya dengan Abraham dan Daud telah mengikatkan diri-Nya kepada bangsa Israel meskipun umat perjanjian-Nya itu telah memberontak. Meskipun Allah harus menghukum dan menyucikan mereka yang berbuat jahat, kerinduan-Nya untuk bangsa itu pada akhirnya akan terwujud (Chisholm Jr. 2005).

Penulis kitab meyakini bahwa providensi, rahmat dan kesetiaan Allah terus berlangsung bagi umatNya. la menyatakan bahwa Allah "bagian"nya, serta menunjukan adanya "pengharapan" akan keselamatan Tuhan. Peneguhan ini diungkapkan pada kalimat "Tuhan adalah baik bagi orang yang berharap kepada-Nya" (Rat. 3:24-26). Penggunaan metafora (gaya bahasa perbandingan) tentang "bagian" ini menggambarkan bahwa Tuhan sebagai tanah pusaka atau warisan yang menyediakan kebutuhan hidup (bdg. Maz. 16:5-6; 73:26; 119:57; 142:6).

Penulis kitab memiliki perspektif yang benar mengenai penderitaan dan disiplin. la menyatakan, "Adalah baik bagi pria memikul kuk pada masa mudanya. Biarlah ia duduk sendirian dan berdiam diri kalau TUHAN membebankannya" (Rat. 3:27-28). Kesadaran penulis terhadap hukuman dan ajaran Tuhan tidaklah semena-mena atau berlaku untuk selamalamanya (Rat. 3:31-39). Namun, keadilan Tuhan menuntut agar dosa dihukum. Seseorang harus menerima disiplin tanpa mengeluh (Rat. 3:2830, 39) dan berpaling kepada Tuhan melalui pertobatan (Rat. 3:40-42). Menaikkan Permohonan untuk Pemulihan 
Respon ketiga atas murka Allah adalah menyampaikan permohonan di dalam doa kepada Allah. Ratapan 5 adalah sebuah doa masyarakat. Doa ini dibagi menjadi dua bagian: ayat 1-18 dan dan ayat 19-22. Ratapan 5:1-18 merupakan doa umat kepada Allah untuk mengingat penderitaan yang dialami. Bagian ini dimulai dengan permohonan langsung kepada Allah: "Ingatlah, ya TUHAN, apa yang terjadi atas kami, pandanglah dan lihatlah akan kehinaan kami” (Rat. 5:1). Umat meminta kepada Allah agar mengingat penderitaan yang mereka telah alami. Kemudian ayat 2-18 diuraikan penderitaan yang telah dan sedang dihadapi. Doa peringatan dalam Alkitab tidak sekedar untuk mengingat masa lalu tetapi selalu melibatkan tindakan resultan, maka doa ini adalah sebuah panggilan bagi Allah untuk bertindak (Ellison 1986).

\section{KESIMPULAN}

Kitab Ratapan adalah kitab yang tidak secara jelas menunjukkan identitas penulisnya. Kitab ini seluruhnya berbentuk puisi. Secara khusus kitab ini bernada keluhan atau ratapan dimana penulis kitab bertindak atas nama pribadi dan mewakili bangsanya untuk menyampaikan keluhan atas penderitaan yang dialami mereka karena murka Allah. Kitab ini juga terdiri dari lima puisi yang disusun secara akrostik dan bertingkat.

Kitab Ratapan ditulis sebagai ungkapan keluhan atau ratapan umat Allah yang sangat menderita oleh penghukuman Allah. Mereka dihukum oleh Allah karena dosa-dosa yang telah dilakukannya. Mereka telah 
melanggar ketetapan Allah, memberontak terhadap firman-Nya, bertindak tidak adil ditengah masyarakat, dan mengandalkan manusia dan tidak berserah kepada Allah. Melalui setiap ratapan, penulis kitab yang mewakili bangsanya mengakui segala pelanggaran dan mengharapkan pemulihan Allah berdasarkan kasih setia, rahmat, dan kesetiaan-Nya.

Kitab Ratapan mengajar orang percaya bahwa: pertama, dosa adalah masalah yang serius. Ketidaktaatan kepada firman Allah akan membawa murka Allah dan penderitaan, bahkan kepada umat-Nya sekalipun. Oleh sebab itu, umat hendaknya belajar untuk terus peka terhadap kehendak Allah melalui ketaatan terhadap firman-Nya. Kedua, sekalipun Allah mengasihi dan berbelas kasihan kepada umat-Nya, tetapi la harus menghukum orang yang sengaja keras kepala dan tidak taat atau patuh kepada-Nya. Hukuman Allah adalah proses pendisiplinan bagi umat agar bertobat dan kembali kepada Allah. Ketiga, umat perlu belajar berdiam diri dihadapan Allah yang benar dan adil itu dengan senantiasa membuka hati bagi Allah. Respon yang tepat adalah bertobat dan menjalani proses pendisiplinan dengan taat. Keempat, umat tetap hidup dalam pengharapan dan doa kepada Allah. Rahmat dan kasih setia Allah menjadi dasar umat untuk tetap berharap dan bersandar kepada Allah.

\section{DAFTAR PUSTAKA}

Arnold, Bill T., and John H. Choi. 2018. A Guide To Biblical Hebrew Syntax. 2nd ed. Cambridge, NY: Cambridge University Press. https://doi.org/10.1017/9781139939591. 
Bracke, J. M. 2000. Jeremiah 30-52 and Lamentations. Louiseville, KY: Westminster/John Knox Press.

Bullock, C. Hassell. 2002. Kitab Nabi-Nabi Perjanjian Lama. Malang: Penerbit Gandum Mas.

Chisholm Jr., Robert B. 2005. "Teologi Kitab Yeremia Dan Ratapan." In A Biblical Theology of the Old Testament: Teologi Alkitabiah Perjanjian Lama, edited by Roy B. Zuck. Malang: Gandum Mas.

Coppes, Leonard J. 1980. "Raham." In Theological Wordbook of the Old Testament, edited by R. Laird Harris, Gleason L. Archer Jr., and Bruce K. Waltke, 841-43. Chicago: Moody Press.

Ellison, H. L. 1986. Lamentations. Edited by Frank E. Gaebelein. The Expositor's Bible Commantary Volume 6: Isaiah, Jeremiah, Lamentation, Ezekiel. Grand Rapids, MI: Zondervan Publishing House.

Ferris Jr., P. W. 1992. The Communal Lament in the Bible and the Ancient Near East. Atlanta: Scholars Press.

Garrett, Duane, and Paul R. House. 2004. Song of Songs and Lamentations. Word Biblical Commentary Volume 23B. Dallas: Word Books.

Gilchrist, Paul R. 1980. "Yatsat." In Theological Wordbook of the Old Testament, edited by R. Laird Harris, Gleason L. Archer, and Bruce K. Waltke, 396. Chicago: Moody Press.

Green, Joel B. 2005. Memahami Nubuatan. Jakarta: Persekutuan Pembaca Alkitab.

Groningen, Gerard Van. 1980a. "Ap." In Theological Wordbook of the Old Testament, edited by R. Laird Harris, Gleason L. Archer Jr., and Bruce K. Waltke, 58. Chicago: Moody Press.

_ 1980b. "Qatsap." In Theological Wordbook of the Old Testament, edited by R. Laird Harris, Gleason L. Archer, and Bruce K. Waltke, 808. Chicago: Moody Press.

Harris, Beau, and Carleen Mandolfo. 2013. "The Silent God in Lamentations." Interpretation: A Journal of Bible and Theology 67, no. 2: 133-43. https://doi.org/10.1177/0020964312473254.

Harris, R. Laird. 1980. "Khesed." In Theological Wordbook of the Old Testament, edited by R. Laird Harris, Gleason L. Archer, and Bruce K. Waltke, 305. Chicago: Moody Press.

Hillers, D. R. 1992. Lamentations: A New Translation with Introduction and Commentary. New York: Doubleday. 
Holladay, William L. 1988. A Concise Hebrew and Aramaic Lexicon of the Old Testament. Grand Rapids, MI: William B. Eerdmans Publishing Company.

King, Philip J., and Lawrence E. Stager. 2010. Kehidupan Orang Israel Alkitabiah. Jakarta: BPK Gunung Mulia.

Klein, William W., Craig L. Blomberg, and Robert L. Hubbard Jr. 2016. Introduction to Biblical Interpretation 2: Pengantar Tafsiran Alkitab. Edited by Timotius Lo. Malang: Literatur SAAT.

Koehler, Ludwig, and Walter Baumgartner. 2000. The Hebrew And Aramaic Lexicon of The Old Testament. Leiden: Koninklijke Brill.

Longman III, Tremper. 1995. "Lament." In Cracking Old Testament Codes: A Guide to Interpreting The Literary Genres of the Old Testament, edited by D. Brent Sandy and Ronald L. Giese Jr., 198. Nashville, Tennesse: Broadman \& Holman Publishers.

Longman III, Tremper, and Raymond B. Dillard. 2006. An Introduction to The Old Testament. Grand Rapids, Ml: Zondervan.

Miller, C. W. 2002. "The Book of Lamentations in Recent Research." Currents in Biblical Research 1, no. 1: 9-29.

Osborne, Grant R. 2006. Spiral Hermeneutika: Pengantar Komprehensif Bagi Penafsiran Alkitab. Edited by Stevy Tilaar. Surabaya: Penerbit Momentum.

Provan, lain. 1991. The New Century Bible Commentary: Lamentations. Grand Rapids: Eermans Publisher Company.

Ryken, Leland, James C. Wilhoit, and Tremper Longman III, eds. 2011a. "Marah, Kemarahan." In Kamus Gambaran Alkitab, 638-39. Surabaya: Penerbit Momentum.

__. eds. 2011b. "Tahir, Pentahiran." In Kamus Gambaran Alkitab, 1058. Surabaya: Penerbit Momentum.

Sriulina, Indah. 2016. "Pendampingan Pastoral Yang Memberdayakan Penyintas Sinabung Yang Mengalami Trauma." Indonesian Journal of Theology 4, no. 2: 194-214.

Subagyo, Andreas B. 2004. Pengantar Riset Kuantitatif \& Kualitatif Termasuk Riset Teologi Dan Keagamaan. Bandung: Yayasan Kalam Hidup.

Thomas, Heath A. 2012. "A Survey of Research on Lamentations (20022012)." Currents in Biblical Research 12, no. 1: 8-38. https://doi.org/10.1177/1476993X12458629.

Waltke, Bruce K., and M. O'Connor. 1990. An Introduction to Biblical 
Hebrew Syntax. Winona Lake, Indiana: Eisenbrauns.

Walvoord, John F., and Roy B. Zuck. 1985. The Bible Knowledge Commentary Volume 1. Wheaton, IL: Victor Books.

White, William. 1980. "Ro'sh." In Theological Wordbook of the Old Testament, edited by R. Laird Harris, Gleason L. Archer Jr., and Bruce K. Waltke, 826. Chicago: Moody Press.

Wiiliamson Jr., Robert. 2015. "Taking Root in the Rubble: Trauma and Moral Subjectivity in the Book of Lamentations." Journal for the Study of the Old Testament 40, no. 1: 7-23. https://doi.org/10.1177/0309089215605787.

Wood, Leon J. 1980. "Haron." In Theological Wordbook of the Old Testament, edited by R. Laird Harris, Gleason L. Archer, and Bruce K. Waltke, 322. Chicago: Moody Press.

- 2005. The Prophets of Israel. Malang: Penerbit Gandum Mas.

Yamauchi, Edwin M. 1988. "Ezra-Nehemiah." In Expositor's Bible Commentary Volume 4. Grand Rapids: Zondervan Publishing House.

Zaluchu, Sonny Eli. 2021. "Metode Penelitian Di Dalam Manuskrip Jurnal IImiah Keagamaan." Jurnal Teologi Berita Hidup 3, no. 2: 249-66. https://doi.org/https://doi.org/10.38189/jtbh.v3i2.93. 